ORIGINAL ARTICLE

\title{
miRNA-223-3p, miRNA- 2909 and Cytokines Expression in COVID-19 Patients Treated with Ivermectin
}

\author{
Noha A. Rezk ${ }^{1 *}$, Ashraf Elsayed Sileem ${ }^{2}$, Doaa Mostafa Gad ${ }^{2}$, Amr Osama Khalil ${ }^{3}$ \\ ${ }^{1}$ Medical Biochemistry Department, Faculty of Medicine, Zagazig University, Egypt \\ ${ }^{2}$ Chest Department, Faculty of Medicine, Zagazig University, Egypt \\ ${ }^{3}$ Radiology Department, Faculty of Medicine, Zagazig University, Egypt \\ *Corresponding \\ author: \\ Noha Rezk \\ Medical Biochemistry \\ Department, Faculty of \\ Medicine, Zagazig \\ University \\ Email: \\ nonnarezk@yahoo.com \\ Submit Date 2021-08-25 \\ Revise Date 2021-10-09 \\ Accept Date 2021-10-30

\section{ABSTRACT} \\ Background: The role of Ivermectin in improving the outcome of coronavirus disease of \\ 2019 (COVID-19) symptoms was reported in several studies, while its effect on the pro- \\ inflammatory cytokines triggering the cytokine storm is still not investigated. This study \\ aimed to investigate the role of Ivermectin on the proinflammatory cytokines in Covid-19 \\ patients and correlated the results with the expression of miR-2909, miR-223-3p. \\ Methods: Three hundred and twenty hospitalized patients with confirmed moderate- \\ severe acute respiratory syndrome coronavirus 2 (SARS-CoV-2) infection were \\ selected. The patients were divided into 2 groups: Group I treated with the Egyptian \\ protocol of COVID-19 including (Ivermectin plus hydroxychloroquine). Group II was \\ treated with the Egyptian protocol, including hydroxychloroquine and no Ivermectin. IL- \\ 6, IL-1b, procalcitonin, and gene expression of miR-2909, miR-223-3p, and Toll-like \\ receptor 4 were done by real-time Polymerase Chain Reaction (PCR). \\ Results: Patients treated with COVID-19 protocol including Ivermectin showed \\ a significant decrease of cytokines levels (IL-6, IL-1, and procalcitonin), when compared \\ with the other group, the cytokines levels improvement were positively correlated \\ with miR-2029 expression and negatively correlated with the expression of miR-223-3p. \\ Moderate ill COVID-19 patients treated with Ivermectin showed a significant decline in \\ mortality rate and duration of hospital stay. \\ Conclusions: Ivermectin is an effective drug in improving the outcome of SARS-CoV-2 \\ patients with a significant decrease in mortality rate through decreasing cytokines \\ expression via controlling miR-2029, miR-233-3p expressions. \\ Keywords: SARS-CoV-2; Ivermectin; miR-223-3p; miR-2029; Covid-19; Cytokines
}

\section{INTRODUCTION}

$\mathrm{O}$ $n$ the $11^{\text {th }}$ of March of the year 2020, the World Health Organization (WHO) declared coronavirus disease of 2019 (Covid-19) a pandemic announcing the beginning of a worldwide health emergency, the first to be seen in contemporary history. By the end of May 2021, the total cases were around 175 million and 3.79 million deaths. In Egypt, the number of announced cases reached 272 thousand with 15,547 deaths [1]. Since the emerging of the pandemic there has been momentous progress in comprehending the pathogenesis of the virus and how it works, however, its rapid spread and the fatality rate are still not sufficiently contained with the emerging of new variants worldwide.
Severe acute respiratory syndrome coronavirus 2 (SARS-CoV-2) infection, the cause of COVID-19, is described to have 2 stages, firstly the entrance of the virus in the tissues and cells which causes the main symptoms and complications [2,3], secondly the "cytokine storm" which is an inflammatory stage instigated by stimulation of STAT-3, IL-6, IL-8, G-CSF, NF-kB, and others pro-inflammatory genes. The attachment of angiotensin-converting enzyme-related carboxypeptidase-2 (ACE2) receptor to the SARS-CoV-2 spike protein is the first signal in the inflammatory stage leading to the activation of the ACE/Ang II/AT1R axis followed by stimulation of IL-6/STATs axis causing $\mathrm{NF}-\kappa \mathrm{B}$ hyper-activation [4,5]. This 
hyper-activation is the trigger of the cytokine storm which causes acute respiratory distress syndrome (ARDS) by affecting the lung tissues in severe cases, and it is positively correlated with the severity of the disease [6].

Several studies detected the increase of several inflammatory cytokines and chemokines in coronavirus infection, mainly IL6, IL $1 \beta$, and IL8, and their increase was correlated with the severity of the infections $[7,8]$. Tackling these inflammatory cytokines is the basis of many clinical trials to abort the cytokine storm. Tolllike receptor (TLR) 4 identifies then connects to lipopolysaccharide (LPS) to start signaling pathways by MyD88-dependent and/or MyD88independent cascades, leading to the stimulation of NF- $\mathrm{NB}$ [9].

The immune and inflammatory promoting genes are expressed with the help of the inducible transcription factor $\mathrm{NF}-\kappa \mathrm{B}$, TLR 4 mediated signaling uses NF- $\kappa \mathrm{B}$ activation to stimulate IL6 and TNF- $\alpha$ expression [10]. It was reported that TLR4 can activate the cytokine's production, therefore its inhibition by neutralizing antibodies may cause a decrease in the production of the inflammatory factors inside the cell [9]. Several studies explored the relationship between the inflammatory signaling pathways and the complication of the COVID19 leading to the notion to investigate the role of MicroRNAs (miRNAs) in the pathogenesis of COVID-19[7,8,9,10].

miRNA is a small non-coding RNA formed of about 19 to 25 nucleotides that functions as gene expression regulators via controlling mRNAs, causing either repression of mRNA translation or post-translation modifications [11]. miRNAs and RNAs complex regulate several biological processes including differentiation, apoptosis, and cell cycle [12]. miRNAs regulate TLR mediated signaling by many mechanisms like attacking the TLR signaling components; or by triggering RNA-sensing TLRs. miR-223 is one of the main miRNAs involved in regulating inflammatory and immune reactions inside the cell by directly targeting TLR mediated signaling and regulating IL-6 pathways [13].
While miR-2909 can be induced by the activation of $N F-\kappa B$ in peripheral blood mononuclear cells [14]. Inflammatory cytokines as TNF- $\alpha$ and IL6 production can be affected by Krueppel-like factor (KLF) 4, which is targeted by miR-2909[15].

The invention of novel medicines might not be the ideal logic with the increasing number of infections and deaths per minute therefore repurposing of drugs is the more rational method for quick results. An anti-parasitic FDAapproved drug named Ivermectin used to treat Lymphatic Filariasis [16] is one of these repurposing drugs. The antiviral effect of Ivermectin was studied in some in vitro studies [17]. It was reported to control RNA virus infection as West Nile and influenza virus by inhibiting the viral proteins and the host nuclear import [18], moreover It was found to have a role in modulation of the inflammatory process and the levels of Transforming Growth Factor-Beta 1 (TGF $\beta$ ) and Vascular Endothelial Growth Factor (VEGF) [19]. In recent studies, it was proposed to be effective against SARS-CoV-2 infection by both in vitro [20] and in vivo [21] trials, on the other hand, another trial reported that it didn't significantly affect the course of early COVID-19 [22]. The mechanism of action of ivermectin in decreasing the complication of COVID-19 and improving its outcome is still not investigated. We aimed to investigate the role of ivermectin in Covid-19 infection, its effect on the inflammatory cytokines and if its action is related to two of the most recent miRNAs implicated in the development of inflammatory reactions $\mathrm{miR}-223-3 \mathrm{P}$, and $\mathrm{miR}-2909$.

\section{METHODS}

\section{Subjects:}

Three hundred and twenty hospitalized patients with confirmed moderate SARS-CoV-2 infection were selected. COVID-19 infection diagnosis was confirmed with at least one positive real-time PCR result from the nasopharyngeal/oropharyngeal swab.

According to the New Coronavirus Pneumonia Prevention and Control Program (6th edition), 
COVID cases were divided into four categories: mild, moderate, severe, critical pneumonia [23]. The patients were divided into 2 groups:

Group I: 160 patients with moderate COVID19 infection treated with management protocol as issued by the Egyptian protocol of COVID-19 November 2020 for moderately ill patients including Ivermectin $6 \mathrm{mg}$ (36 mg on day 0 -36) [24], plus hydroxychloroquine (400 mg / 12 hours for one day followed by $200 \mathrm{mg}$ every 12 hours for 9 days) [25].

Group II: 160 patients with moderate COVID19 infection treated with management protocol as issued by the Egyptian protocol of COVID-19 May 2020 for moderate ill patients including hydroxychloroquine (400 mg / 12 hours for one day followed by $200 \mathrm{mg}$ every 12 hours for 9 days) [26].

Patients younger than 18 years, as well as pregnant and lactated females, were excluded from the study. Moderate cases were selected according to the following criteria: fever, respiratory tract symptoms, GIT symptoms, and pneumonia manifestations seen in chest imaging.

The two groups were followed up daily clinically and by laboratory investigations for 2 weeks and by radiological imaging after 2 weeks. They were followed up according to the time of SARS-CoV-2 swab negative result, disease progression to severe cases (pneumonia to severe respiratory distress syndrome), duration of hospital stay, clinical, radiological improvement, and mortality rate.

After hospital release, the patients were followed up for another 2 weeks by regular phone calls daily until they returned to their usual state of health or were readmitted to the hospital.

Criteria of severe COVID-19 cases: Respiratory rate over 30/min, blood oxygen saturation < $93 \%$, required an FIO2 of $50 \%$ or more, lung infiltrates over $50 \%$ of the lung or rapid progression within 1- 2 days, patients need high flow oxygen either noninvasive or invasive mechanical ventilation.

Two consecutive nasopharyngeal/ oropharyngeal swabs with negative PCR results for SARS-CoV-2 taken 2 days apart, or clinical and laboratory test improvement, were considered as an endpoint.

Written informed consent was obtained from all participants, the study was approved by the research ethical committee of Faculty of Medicine, Zagazig University. The study was done according to The Code of Ethics of the world Medical Association (Declaration of Helsinki) for studies involving humans.

\section{Methods:}

\section{Biochemical measurement}

Ten $\mathrm{ml}$ of peripheral blood was obtained from all the patients on admission and after one week of treatment. $4 \mathrm{~mL}$ blood was obtained on EDTA-containing tubes, and $6 \mathrm{~mL}$ remained for 10 minutes to clot, and after that was centrifuged. The serum samples were isolated and stored at $-20^{\circ} \mathrm{C}$ till the assay. Complete Blood Count (CBC) was done by hematology analyzer (mindray, BC 20s), C reactive protein (CRP) (Atlas Biotech), Ferritin (ELISA, Pishtaz diagnostic kit), D dimer (Unicell- quantitative rapid test), Lactate dehydrogenase (LDH) (Spectrum, REF 283003), interleukin-6 (IL-6), pro-calcitonin (PCT) and IL-1b were estimated by enzyme-linked immunosorbent assay ELIZA (R\&D) was done on admission and repeated after one week of treatment.

\section{TLR-4 quantitative real-time polymerase chain reaction}

Total RNA was extracted from white blood cells using [GenElute TM Mammalian Total RNA Miniprep Kit; Sigma-Aldrich, USA]. Isolated RNA was reverse transcribed using an RT-PCR kit [TOYOBO, Osaka, Japan] according to the manufacturer's instructions. To assess mRNA expression of LTR4, qRT-PCR was done using SYBR green on a [StratageneTMMx3005P] qPCR instrument [Agilent Technologies]. Primers used forward 5'- TGGACCTGCGATTTAATCCC 3'- and reverse 5' GTCTGGATTTCAGAGCAGGA 3' for TLR4, $F$ 5'TGCTGTCTCTGAGTTTGATGTATCT-3' and R5'- TCTCTGCTCCCCACCTCTATAG -3' for $\beta 2 \mathrm{~m}$. Reactions were done as follows: $95^{\circ} \mathrm{C}$ for 
$30 \mathrm{sec}, 40$ cycles of $95^{\circ} \mathrm{C}$ for $5 \mathrm{sec}$, and $60^{\circ} \mathrm{C}$ for $34 \mathrm{sec}$. Relative expression of genes was calculated according to the $\Delta \mathrm{Ct}$ method [27].

\section{miRNA extraction assay}

Isolation of total RNA was done according to the manufacturer's instructions of the miRNeasy extraction kit (Qiagen, Valencia, CA) by using $250 \mu \mathrm{l}$ of QIAzol lysis reagent for $5 \mathrm{~min}$ at room temperature. Then, $200 \mu \mathrm{L}$ of chloroform was added and vortexed for $15 \mathrm{sec}$, incubating the samples for $3 \mathrm{~min}$ at room temperature, then centrifuged at $14,000 \mathrm{x}$ g at $4 \circ \mathrm{C}$ for $15 \mathrm{~min} .600$ $\mu \mathrm{L}$ were pipetted in miRNeasy Mini spin column and centrifuged at $8000 \mathrm{x}$ g for $60 \mathrm{sec}$ followed by addition of buffer RWT then buffer RPE before centrifugation at $8000 \mathrm{xg}$ for $2 \mathrm{~min} .20 \mu \mathrm{L}$ of eluted miRNA was reverse transcribed by incubation for 30 minutes at $25^{\circ} \mathrm{C}, 30$ minutes at $42{ }^{\circ} \mathrm{C}, 5$ minutes at $85{ }^{\circ} \mathrm{C}$, and afterward kept up at $4 \circ \mathrm{C}$ using the miRNeasy Reverse Transcription Kit (Qiagen, Valencia, CA) as indicated by the manufacturer's instructions [28].

Real Time-PCR quantification of miR-2909, miR-223-3p

Quantitative real-time polymerase chain reaction test using SYBR Green PCR kit (Qiagen, Hilden, Germany) on (StratageneTMMx3005P) qPCR instrument (Agilent Technologies) was performed. The sequence of the primers used were h-miR-223$3 \mathrm{p}$ forward 5'ACACTCCAGCTGGGTGTCAGTTTGTCAA AT-3', reverse 5'CTCAACTGGTGTCGTGGAGTCGGCAATT CAGTTGAGTGGGGTAT-3' and h-miR-2909 $\mathrm{F}$

5'ACACTCCAGCTGGGGTTAGGGCCAAC ATC-3',

$\mathrm{R}$

CTCAACTGGTGTCGTGGAGTCGGCAATT

CAGTTGAGCCAAGAGA-3'. The reactions were done as follow: $50^{\circ} \mathrm{C}$ for $2 \mathrm{~min}, 95^{\circ} \mathrm{C}$ for $10 \mathrm{~min}$; and 40 cycles of $95^{\circ} \mathrm{C}$ for $30 \mathrm{~s}$, and $60^{\circ} \mathrm{C}$ for $30 \mathrm{~s}$. The relative expression of $\mathrm{miR}-223-3 \mathrm{P}$, miR-2909, was calculated in relation to the level of internal control U6. The data were analyzed using the $\Delta \mathrm{Ct}$ method [27].

Statistical analysis:

Data were analyzed with SPSS version 15.0 (statistical package for the Social Science, Chicago, IL). Differences in the frequencies in the studied groups were analyzed using the chisquare (X2) test. Levels of serum miRNA were expressed as mean \pm SD. The significant difference between the groups was determined using Student's t-test. Pearson correlation analysis was employed to assess the correlation between different parameters in the studied subjects. A difference was significant at the Pvalue <0.05. P-value was adjusted after Bonferroni correction.

\section{RESULTS}

Demographic data of the patients and control groups

The studied groups did not differ as regards age, sex, smoking, comorbidities, symptoms, and biochemical parameters at the time of admission (p > 0.05) (Table 1).

Serum levels of different parameters in the studied groups one week after treatment.

We detected that IL-6, Il-1b, and procalcitonin were significantly increased in group II (hydroxychloroquine only) compared to group I (Ivermectin plus hydroxychloroquine $)(\mathrm{p}=$ 0.001, 0.11, 0.008 respectively). Also, Toll-like receptor expression and miR-2029 expression were significantly increased in group II compared to group I ( $\mathrm{p}=0.01 .0 .03)$, while, miR223-3p gene expression was significantly decreased in group II compared to group I ( $\mathrm{p}=$ 0.023) (Table 2).

Correlation between different parameters in the studied groups.

We observed that miR-223-3p expression level was inversely correlated with IL-6, IL-1b, procalcitonin and TLR-4 in the studied groups ( $\mathrm{r} 2=0.91,0.82,0.79,0.93)$, while, miR-2029 expression level was positively correlated with IL-6, IL-1b, procalcitonin and TLR-4 in the studied groups $(\mathrm{r} 2=-0.83,-0.77,-0.89,-0.94)$ (Table 3).

Prognosis of the disease in the studied groups 
We observed a statistically significant improvement associated with a significant rapid SARS-CoV-2 RT-PCR conversion to a negative result in group I compared to group II after 2 weeks of treatment $(p=0.013,0.01$

Table 1: Clinical characteristics of the studied groups

\begin{tabular}{|c|c|}
\hline & $\begin{array}{l}\text { Group I: COVID-19 cases } \\
\text { treated with } \\
\text { hydroxychloroquine and } \\
\text { Ivermectin } \\
(n=160)\end{array}$ \\
\hline Age & $50.9 \pm 14.7$ \\
\hline \multicolumn{2}{|l|}{ Sex } \\
\hline Female $\mathrm{n}(\%)$ & $83(51.8)$ \\
\hline Male $\quad \mathrm{n}(\%)$ & $77(48.2)$ \\
\hline Smoker n (\%) & $43(26.9)$ \\
\hline \multicolumn{2}{|l|}{ Comorbidities } \\
\hline Diabetes n $(\%)$ & $34 / 113(30.3)$ \\
\hline Renal n (\%) & $11 / 113(10.2)$ \\
\hline Cardiac $\mathrm{n}(\%)$ & $10 / 113(8.1)$ \\
\hline Obesity $\mathrm{n}(\%)$ & $14 / 113(12.3)$ \\
\hline Hypertension n (\%) & $12 / 113(10.8)$ \\
\hline Cancer $\mathrm{n}(\%)$ & $9 / 113(7.9)$ \\
\hline Thyroid n $(\%)$ & $1 / 113(0.9)$ \\
\hline Neurologic n $(\%)$ & $1 / 113(0.9)$ \\
\hline Pulmonary n (\%) & $21 / 113(18.6)$ \\
\hline \multicolumn{2}{|l|}{ Presenting symptoms } \\
\hline Fever n $(\%)$ & $130 \quad(81.2)$ \\
\hline Cough n $(\%)$ & $96 \quad(60)$ \\
\hline Fever plus cough n (\%) & $69(43.1)$ \\
\hline Dyspnea n (\%) & 34 (21.3) \\
\hline Headache n $(\%)$ & $58(36.3)$ \\
\hline Loss of appetite n (\%) & $51(31.9)$ \\
\hline Nausea n $(\%)$ & $21(13.1)$ \\
\hline Diarrhea n (\%) & $18(11.3)$ \\
\hline Abdominal pain $\mathrm{n}(\%)$ & $9(5.6)$ \\
\hline Chest pain $\mathrm{n}(\%)$ & $16(10)$ \\
\hline Anosmia n (\%) & $4(2.5)$ \\
\hline \multicolumn{2}{|l|}{ Biochemical profile } \\
\hline $\mathrm{CRP}(\mathrm{mg} / \mathrm{L})$ & $49.4 \pm 14.3$ \\
\hline Ferritin (ng/ml) & $171 \pm 18.5$ \\
\hline $\mathrm{D}$ dimer $(\mu \mathrm{g} / \mathrm{ml})$ & $5.0 \pm 2.1$ \\
\hline Lactate dehydrogenase (U/L) & $304 \pm 105.8$ \\
\hline Lymphocyte count $/ \mathrm{mm}^{3}$ & $1.05 \pm 0.56$ \\
\hline Total leucocytic count $/ \mathrm{mm}^{3}$ & $4.79 \pm 2.36$ \\
\hline IL-6 (pg/ml) & $72.5 \pm 20.2$ \\
\hline
\end{tabular}

respectively). After 4 weeks of observation, we detected a significant decrease in the number of subjects who were readmitted to the hospital in group I compared to group II $(\mathrm{p}=0.041)$ (Table 4).
Group II: COVID-19 cases

treated with

hydroxychloroquine

$(\mathrm{n}=\mathbf{1 6 0})$

$53.1 \pm 12.6$

0.15

$80(50)$

0.13

$80(50)$

$45(28.1)$

0.23

35/132 (26.5) 0.89

$17 / 132(12.8) \quad 0.82$

$14 / 132(10.6) \quad 0.78$

$15 / 132(11.4) \quad 0.91$

$\begin{array}{ll}11 / 132(8.4) & 0.85\end{array}$

$8 / 132(6.1) \quad 0.9$

$3 / 132(2.3) \quad 0.6$

$4 / 132(3.0) \quad 0.57$

25/132 (18.9) 0.96

$121(75.6) \quad 0.1$

$101(63.1) \quad 0.3$

$74(46.3) \quad 0.34$

$30(18.7) \quad 0.26$

$62(38.8) \quad 0.4$

$46(28.8) \quad 0.39$

$17(10.6) \quad 0.25$

25 (15.6) 0.2

$12(7.5) \quad 0.21$

$13(8.1) \quad 0.22$

$3(1.9) \quad 0.13$

$\begin{array}{ll}51.6 \pm 17.3 & 0.86\end{array}$

$169.4 \pm 13.6 \quad 0.76$

$4.4 \pm 1.8 \quad 0.80$

$297 \pm 101.8 \quad 0.6$

$1.18 \pm 0.61 \quad 0.73$

$5.09 \pm 2.27 \quad 0.71$

\begin{tabular}{l|l}
$76.3 \pm 18.2$ & 0.56
\end{tabular} 


\begin{tabular}{|c|c|c|c|}
\hline & $\begin{array}{l}\text { Group I: COVID-19 cases } \\
\text { treated with } \\
\text { hydroxychloroquine and } \\
\text { Ivermectin } \\
(n=160)\end{array}$ & $\begin{array}{l}\text { Group II: COVID-19 cases } \\
\text { treated with } \\
\text { hydroxychloroquine } \\
(\mathrm{n}=160)\end{array}$ & $P$ \\
\hline $\mathrm{Il}-1 \mathrm{~b}(\mathrm{pg} / \mathrm{ml})$ & $45.7 \pm 8.2$ & $40.5 \pm 7.8$ & 0.43 \\
\hline Procalcitonin (ng/ml) & $0.64 \pm 0.14$ & $0.75 \pm 0.15$ & 0.61 \\
\hline
\end{tabular}

Table 2: Serum levels of different parameters in the studied groups one week after treatment

\begin{tabular}{|c|c|c|c|}
\hline & $\begin{array}{l}\text { Group I :COVID-19 } \\
\text { cases treated with } \\
\text { Ivermectin and } \\
\text { hydroxychloroquine } \\
(\mathrm{N}=160)\end{array}$ & $\begin{array}{l}\text { Group II :COVID-19 } \\
\text { cases treated with } \\
\text { hydroxychloroquine } \\
(\mathrm{N}=160)\end{array}$ & $p$ \\
\hline IL-6 (pg/ml) & $34.6 \pm 9.8$ & $53.5 \pm 14.2$ & $0.001 *$ \\
\hline $\mathrm{Il}-1 \mathrm{~b}(\mathrm{pg} / \mathrm{ml})$ & $15.6 \pm 4.3$ & $25.7 \pm 4.2$ & $0.011 *$ \\
\hline Procalcitonin (ng/ml) & $0.16 \pm 0.03$ & $0.44 \pm 0.11$ & $0.008^{*}$ \\
\hline TLR4 expression & $0.89 \pm 0.11$ & $1.40 \pm 0.20$ & $0.01 *$ \\
\hline miR-223-3p expression & $0.74 \pm 0.10$ & $0.52 \pm 0.03$ & $0.03 *$ \\
\hline miR-2909 expression & $0.93 \pm 0.09$ & $1.35 \pm 0.16$ & $0.026^{*}$ \\
\hline CRP (mg/L) & $16.8 \pm 2.1$ & $30.3 \pm 3.6$ & $<0.001 *$ \\
\hline Ferritin (ng/ml) & $98.8 \pm 21.4$ & $101.5 \pm 15.3$ & 0.5 \\
\hline $\mathrm{D}$ dimer $(\mu \mathrm{g} / \mathrm{ml})$ & $0.7 \pm 0.16$ & $1.4 \pm 0.21$ & $<0.001 *$ \\
\hline $\begin{array}{l}\text { Lactate dehydrogenase } \\
\text { (U/L) }\end{array}$ & $176 \pm 45.8$ & $185 \pm 51.8$ & 0.61 \\
\hline $\begin{array}{l}\text { Lymphocyte count / } \\
\mathrm{mm}^{3}\end{array}$ & $1.48 \pm 0.51$ & $1.15 \pm 0.46$ & $0.01 *$ \\
\hline $\begin{array}{l}\text { Total leucocytic } \\
\text { count } / \mathrm{mm}^{3}\end{array}$ & $6.07 \pm 2.17$ & $4.29 \pm 2.36$ & $0.01 *$ \\
\hline
\end{tabular}

*A difference was significant at the P-value <0.05. P-value was adjusted after Bonferroni correction.

Table 3: Correlation between plasma miR-233-3p, miR-2029 expression and different parameters in the studied subjects

\begin{tabular}{|c|c|c|c|c|}
\hline & miR- & & miR & pression \\
\hline & $\mathbf{r}^{2}$ & p & $\mathbf{r}^{2}$ & p \\
\hline IL-6 (pg/ml) & -0.83 & $<0.001$ & 0.91 & $<0.001 *$ \\
\hline Il-1b (pg/ml) & -0.77 & $<0.01$ & 0.82 & $<0.001 *$ \\
\hline
\end{tabular}




\begin{tabular}{|c|c|c|c|c|}
\hline $\begin{array}{l}\text { Pro-calcitonin } \\
(\mathrm{ng} / \mathrm{ml})\end{array}$ & -0.89 & $<0.001$ & 0.79 & $<0.01 *$ \\
\hline $\begin{array}{l}\text { TLR4 } \\
\text { expression }\end{array}$ & -0.94 & $<0.001$ & 0.93 & $<0.001 *$ \\
\hline
\end{tabular}

Table 4: Prognostic markers of Covid-19 outcome in the studied groups after 2 weeks

\begin{tabular}{|ll|l} 
Group I: COVID-19 & Group II: COVID- & $p$ \\
cases treated with & 19 cases not treated \\
Ivermectin and & with \\
hydroxychloroquine & hydroxychloroquine \\
$(\mathrm{N}=160)$ & $(\mathrm{N}=158 *)$
\end{tabular}

\section{Clinical outcomes}

Improved n (\%)

Progressed n (\%)

RT-PCR conversion (days)
$152(95)$
$8 \quad(5)$
$6.4 \pm 1.2$
$142(90.6)$
$16(9.4)$
$8.8 \pm 3.5$

0. $013 *$
$0.01 *$

*A difference was significant at the P-value $<0.05$. P-value was adjusted after Bonferroni correction. ** Number of cases decreased due to the death of 2 patients

Table 5: Prognostic markers of Covid-19 outcome in the studied groups after 4 weeks

\begin{tabular}{|ll|l|}
\hline Group I: COVID-19 & Group II: COVID- & $p$ \\
cases treated with & 19 cases treated \\
Ivermectin and & with \\
hydroxychloroquine. & hydroxychloroquine \\
$(\mathrm{N}=145 *)$ & $(\mathrm{N}=138 *)$
\end{tabular}

\section{Clinical outcomes}

$0.041 *$

$118(85.5)$

\section{$20(14.5)$ \\ Readmitted to hospital n (\%) $14 \quad(9.6)$}

*A difference was significant at the P-value $<0.05$. P-value was adjusted after Bonferroni correction.

**We could not reach all the 160 individuals in each group, so the number written is the number of cases we successfully reconnected with.

\section{DISCUSSION}

The role of Ivermectin in improving the outcome of COVID-19 symptoms was studied in several studies, some of which stated its efficiency in improving the outcome of Coronavirus infection $[20,21,29]$, while others question its value as an effective treatment of COVID-19 cases [22]. Ivermectin has drawn global awareness for its role in the management of COVID-19; it was listed in the management protocol for COVID19 patients in many countries including Peru, Bolivia, Paraguay, Colombia [30], and Egypt [25]. After incorporating Ivermectin in the
Egyptian protocols for the management of COVID-19 [25], this study tried to assess its impact on the cytokine storm, which is connected to many symptoms and complications of Coronavirus infection, and as microRNAs are documented to be implicated in the expression of chemokine, cytokines, and growth factors [31], It investigated the expression of two of the most important miRNAs implicated in the TLR4/TLR2/NF- $\kappa$ B/STAT3 signaling pathway [32], which is one pathway correlated with the cytokine storm and correlated their levels with 
the main inflammatory cytokines to deduce the mechanism of Ivermectin actions.

There was a statistically significant improvement associated with a significant decline in mortality rate and duration of hospital stay in groups I (Ivermectin plus hydroxychloroquine) compared to group II (hydroxychloroquine only), also, there was significant rapid SARS-CoV-2 RT-PCR conversion to a negative result in group I compared to group II, these results confirmed what other researchers concluded in their previous trials including, Chowdhury et al. [33], Rajter et al. [34], Behera et al. [35] and our colleague Waheed Shouman [36] who reported that ivermectin has a highly significant role in the protection against SARS-CoV-2 infection and that there was no mortality or serious adverse events because of ivermectin in the intervention group. However, a study by LópezMedina et al. [22] didn't find any significant clinical benefit of ivermectin on COVID-19 cases.

An in-vitro study by Clay et al. [20] reported the reduction of SARS-CoV-2 viral RNA by approximately 5000 -fold when 5 - $\mu \mathrm{M}$ ivermectin was added to the infected cells, however, another study stated that the in-vitro used concentrations are hard to be reached in human plasma and lungs [37] and it may be not safe [38]. Meanwhile, Rajter et al. [34] confirmed that a dose of $200 \mu \mathrm{g} / \mathrm{kg}$ was effective in improving the outcome of severe coronavirus infection.

Our study found that IL-6, IL-1b, pro-calcitonin, and Toll-like receptor expression were significantly increased in group II compared to group I proving our hypothesis that Ivermectin has a role in tackling the cytokine storm by interfering with the proinflammatory cytokine these results are in congruence with the findings of Yan et al. [39] who reported that ivermectin is an effectual suppressor of inflammation and can be used in the treatment of allergic diseases by decreasing the recruitment of immune cells and diminishing the cytokines production, Zhang et al. [40] proved that ivermectin can inhibit lipopolysaccharide (LPS)-induced inflammation by blocking NF-kB pathway and decrease the production of tumor necrosis factor-alpha (TNFalpha), IL-6 and interleukin-1ss (IL-1ss) and suppress translocation of NF-kB. Sohn et al. [41] detected a link joining TLR4 signaling and inflammation in COVID-19 and leading to the development of new therapeutic methods pursuing TLR4-mediated inflammation.

miR-2029 expression was detected to be significantly higher in group II compared to group I, while, miR-223-3p gene expression was significantly decreased in group II compared to group I, meanwhile miR-223-3p expression level was inversely correlated with IL-6, IL-1b, procalcitonin in the studied groups, while, miR202 expression level was positively correlated with IL-6, IL-1b, procalcitonin in the studied groups, As far as we know this is the first study investigating miR-2029 and miR-223-3p expression and correlating their levels with Ivermectin use and COVID-19 infection, Wu et al. [32] detected the relation between Lipopolysaccharide (LPS), miR-223-3P, miR2909 and pro-inflammatory cytokines via TLR 4/TLR2/ NF- $\kappa$ B/ STAT 3 signaling pathway where LPS decrease the expression of both miRNAs while IL-6 stimulation reduce miR223-3P expression leading to the activation of STAT3 which directly targeted TLR4 increasing the pro-inflammatory cytokine production, while miR-2909, NF- $\kappa \mathrm{B}$ dependent, pursued Krueppel-like factor 4 regulating the production of pro-inflammatory cytokines. miR-223 has been reported to controls STAT3 expression and IL-6 expression [42], IL-6 signaling regulation occurs by making STAT3 increase TLR dependent inflammatory reactions [43]. It was reported that miR-223 restrain IL- 6 and TNF- $\alpha$ expression in macrophages infected with Helicobacter pylori [44]. TLR4/NF- $\kappa \mathrm{B}$ pathway can be negatively regulated by miR-223 which can up-regulate PI3K/AKT signaling pathway leading to TLR4/MAPK/NF- $\kappa \mathrm{B}$ pathway block [45]. miR-2909 was proved to regulate genes implicated in inflammation and immunity, and that it is induced by the activation of $\mathrm{NF}-\kappa \mathrm{B}$ [14], 
increasing its expression led to increased IL-6 and TNF- $\alpha$ production by targeting KLF4 [15].

\section{Conclusions}

In this study, we showed that Ivermectin is an effective drug in improving the outcome of SARS-CoV-2 patients with a significant decrease in mortality rate through decreasing cytokines expression via controlling miR-2029, miR-233-3p expressions.

Competing interests: No conflict of interest. Funding: No funding source.

Ethical approval (including reference number): Zagazig University ethical committee and Faculty of Medicine International Review Board (IRB) approved this study (ZU IRP \#7890/26-8-2020)

\section{REFERENCES}

1. WHO Timeline-COVID-19.https://www.who.int/newsroom/detail/22-02-2021-who-timeline\%2D\%2D-covid-

19. (Accessed 22 February 2021)

2. Pascarella G, Strumia A, Piliego C, Bruno F, Del Buono $\mathrm{R}$, Costa F, et al. COVID-19 diagnosis, and management: a comprehensive review. J Intern Med. 2020; 288: 192206.

3. Lundstrom K, Seyran M, Pizzol D, Adadi P, Mohamed Abd El-Aziz T, Hassan et al.. Viewpoint: Origin of SARSCoV-2. Viruses. 2020; 22 (11):1203.

4. Mahmudpour M, Roozbeh J, Keshavarz M, Farrokhi S, Nabipour I. COVID-19 cytokine storm: The anger of inflammation. Cytokine 2020;133:151- 155.

5. Seyran M, Takayama K, Uversky VN, Lundstrom K, Palù $\mathrm{G}$, Sherchan SP, et al. The structural basis of accelerated host cell entry by SARS-CoV- $\uparrow$. FEBS J. 2020 2(10).1111/febs.15651.

6. Chi Y, Ge Y, Wu B, Zhang W, Wu T, Wen T, et al. Serum Cytokine and Chemokine profile in Relation to the Severity of Coronavirus disease 2019 (COVID-19) in China. J Infect Dis. 2020;222:746-54.

7. Aggarwal A, Baker CS, Evans TW, Haslam PL. G-CSF and IL-8 but not GM-CSF correlate with severity of pulmonary neutrophilia in acute respiratory distress syndrome. Eur Respir J. 2000;15:895-901.

8. Del Valle DM, Kim-Schulze S, Hsin-Hui H, Beckmann ND, Nirenberg S, Wang B, et al. An inflammatory cytokine signature helps predict COVID-19 severity and death. Nat Med. 2020;26:1636-43.

9. Peng SC, Wong DS, Tung KC, Chen YY, Chao CC, Peng $\mathrm{CH}$, et al. Computational modeling with forward and reverse engineering links signaling network and genomic regulatory responses: NF-kappaB signaling-induced gene expression responses in inflammation. BMC Bioinformatics. 2010; 11:308-21. pmid:20529327.
10. Garibotto G, Carta A, Picciotto D, Viazzi F, Verzola D. Toll-like receptor-4 signaling mediates inflammation and tissue injury in diabetic nephropathy. J Nephrol. 2017;30 (6):719-727. pmid:28933050

11. Alvarez-Garcia I, Miska EA. MicroRNA functions in animal development and human disease. Development 2005;132: 4653-62.

12. Lim LP, Lau NC, Garrett-Engele P, Grimson A, Schelter $\mathrm{JM}$, Castle J, et al. Microarray analysis shows that some microRNAs downregulate large numbers of target mRNAs. Nature 2005; 433: 769-73.

13. Slomiany BL, Slomiany A. Role of LPS-elicited signaling in triggering gastric mucosal inflammatory responses to $\mathrm{H}$. pylori: modulatory effect of ghrelin. Inflammopharmacology. 2017; 25(4):415-429. pmid:28516374

14. Sharma M, Sharma S, Arora M, Kaul D. Regulation of cellular Cyclin D1 gene by arsenic is mediated through miR-2909. Gene. 2013; 522(1):60-4. pmid:23562784

15. Arora M, Kaul D, Sharma YP. Human coronary heart disease: importance of blood cellular miR-2909 RNomics. Mol Cell Biochem. 2014; 392(1-2):49-63. pmid:24634009

16. Mastrangelo E, Pezzullo $M$ and De Burghgraeve T. Ivermectin is a potent inhibitor of flavivirus replication specifically targeting NS3 helicase activity: new prospects for an old drug. J Antimicrob Chemother. 2012; 67(8):1884-1894.

17. Götz, V., Magar, L. and Dornfeld, D. Influenza A viruses escape from MxA restriction at the expense of efficient nuclear vRNP import. Sci Rep 6, 23138 (2016).

18. Lundberg L, Pinkham C, Baer A, Amaya M, Narayanan A, Wagstaff KM, et al. Nuclear import and export inhibitors alter capsid protein distribution in mammalian cells and reduce Venezuelan Equine Encephalitis Virus replication, Antiviral Research 2013; 100(3): 662-672.

19. Sia, D.K., Mensah, K.B. and Opoku-Agyemang, T. Mechanisms of ivermectin-induced wound healing. BMC Vet Res 2020; 16, 397 https://doi.org/10.1186/s12917-020-02612-z

20. Caly L, Druce JD, Catton MG, Jans DA and Wagstaff KM. The FDA-approved drug ivermectin inhibits the replication of SARS-CoV-2 in vitro. Antiviral Res. 2020. https://doi.org/ 10.1016/j.antiviral.2020.104787

21. Behera P, Patro BK, Singh AK, Chandanshive PD, S. R. $\mathrm{R}$, Pradhan SK, et al. Role of ivermectin in the prevention of SARS-CoV-2 infection among healthcare workers in India: A matched case-control study. PLoS ONE 2021; 16(2): e0247163.

22. López-Medina E, López P and Hurtado IC, Effect of Ivermectin on Time to Resolution of Symptoms Among Adults With Mild COVID-19: A Randomized Clinical Trial. JAMA. 2021;325(14):1426-1435

23. State Council of the People's Republic of China. The notice of launching guideline on diagnosis and treatment of the novel coronavirus pneumonia (6th edition) [in 
Chinese];

2020

http://www.gov.cn/zhengce/zhengceku/2020-02/19/ content_5480948.htm [accessed 2 April 2020]

24. Guzzo, C.A. Safety, tolerability, and pharmacokinetics of escalating high doses of ivermectin in healthy adult subjects. 2002; Clin. Pharmacol. 42, 1122-1133.

25. Management protocol for COVID-19 patients. Egyptian Ministry of Health. Version 1.4 /November 2020. Available at:https://www.researchgate.net/publication/345813633_ Management_Protocol_for_COVID19_Patients_MoHP_ Protocol_for_COVID19_November_2020,

26. Management protocol for COVID-19 patients. Egyptian Ministry of Health. Version $1.4 / 30^{\text {th }}$ May 2020. Available at: http://www.mohp.gov.eg/JobsDetails.aspx?job id=30 $\underline{61}$

27. Livak, K. and Schmittgen, T. Analysis of Relative Gene Expression Data Using RealTime Quantitative PCR and the 22DDCt method. Methods 2001; 25, 402-408

28. Margariti, A., Zampetaki, A., Xiao, Q., Zhou, B., Karamariti, E., et al. Histone deacetylase 7 controls endothelial cell growth through modulation of betacatenin. Circ. Res. 2010; 106, 1202-1211.

29. El Diba N and Alib M. The broad-spectrum antiparasitic ivermectin against COVID-19. Kasr Al Ainy Med J 2020; 26:37-40.

30. Chaccour CJ, Brew J, Garcia-Basteiro A. Ivermectin and COVID-19: how a flawed database shaped the pandemic response of several Latin-American Countries - Blog ISGlobal, 2020 19/6/2020.

31. Palanisamy V, Jakymiw A, Van Tubergen EA, D'Silva NJ, Kirkwood KL. Control of Cytokine mRNA Expression by RNA-binding Proteins and microRNAs. J Dent Res 2012; 91:651-8.

32. Wu J, Niu P, Zhao Y, Cheng Y, Chen W, Lin L, et al. Impact of miR-223-3p and miR-2909 on inflammatory factors IL-6, IL-1ß, and TNF- $\alpha$, and the TLR4/TLR2/NF$\kappa \mathrm{B} / \mathrm{STAT} 3$ signaling pathway induced by lipopolysaccharide in human adipose stem cells. PLoS ONE 2019; 14(2): e0212063.

33. Chowdhury A, Shahbaz M, Karim M, Islam J, Dan G, Shuixiang H. A Comparative Study on IvermectinDoxycycline and Hydroxychloroquine-Azithromycin Therapy on COVID-19 Patients. EJMO. 2021; 5(1): 63-70

34. Rajter JC, Sherman MS, Fatteh N, Vogel F, Sacks J, Rajter JJ. Use of Ivermectin Is Associated with Lower Mortality in Hospitalized Patients With Coronavirus Disease 2019: The Ivermectin in COVID Nineteen Study. Chest. 2021;159(1):85-92.

\section{To Cite:}

Rezk, N., Elsayed Sileem, A., Gad, D., Khalil, A. miRNA-223-3p, miRNA- 2909 and Cytokines Expression in COVID-19 Patients Treated with Ivermectin. Zagazig University Medical Journal, 2022; (573 -582): -. doi: 10.21608/zumj.2021.92746.2329
35. Behera P, Patro BK, Singh AK, Chandanshive PD, S R R, Pradhan SK, et al. Role of ivermectin in the prevention of SARS-CoV-2 infection among healthcare workers in India: A matched case-control study. PLoS One. $2021 \mathrm{Feb}$ 16;16(2):e0247163

36. Shouman W. Use of Ivermectin as a Prophylactic Option in Asymptomatic Family Close Contact for Patient With COVID-19. ClinicalTrials.gov Report No.: NCT04422561 [Internet]. 2020 Aug Available from: https://clinicaltrials.gov/ct2/show/NCT04422561.

37. Bray M, Rayner C, Noël F, Jans D, Wagstaff K. Ivermectin and COVID-19: a report in antiviral research, widespread interest, an FDA warning, two letters to the editor and the authors' responses. Antiviral Res. 2020;178:104805.

38. Momekov G, Momekova D. Ivermectin as a potential COVID-19 treatment from the pharmacokinetic point of view: antiviral levels are not likely attainable with known dosing regimens. Biotechnol Biotechnol Equipment. 2020

39. Yan S., Ci X., Chen N., Chen C., Li X., Chu X. et al. Antiinflammatory effects of ivermectin in mouse model of allergic asthma. Res. 2011;60:589-596.

40. Zhang X., Song Y., Ci X., An N., Ju Y., Li H., et al. Ivermectin inhibits LPS-induced production of inflammatory cytokines and improves LPS-induced survival in mice. Res. 2008;57:524-529.

41. Sohn KM, Lee SG, Kim HJ, Cheon S, Jeong H, Lee J, et al.. COVID-19 Patients Upregulate Toll-like Receptor 4mediated Inflammatory Signaling That Mimics Bacterial Sepsis. J Korean Med Sci. 2020 Sep 28;35(38):e343.

42. Dorhoi A, Iannaccone M, Farinacci M, Fae' KC, Schreiber J, Moura-Alves P, et al. MicroRNA-223 controls susceptibility to tuberculosis by regulating lung neutrophil recruitment. J Clin Invest. 2013; 123 (11):4836-48.

43. Chen Q, Wang H, Liu Y, Song Y, Lai L, Han Q, et al. Inducible microRNA-223 down-regulation promotes TLR-triggered IL- 6 and IL- $1 \beta$ production in macrophages by targeting STAT3. PLoS One. 2012; 7(8): e42971.

44. Wang J, Wu J, Cheng Y, Jiang Y and Li G Overexpression of microRNA-223 inhibited the proinflammatory responses in Helicobacter pyloriinfection macrophages by down-regulating IRAK-1. Am J Transl Res. 2016; 8(2):615-22. PMID: 27158353

45. Wang J, Bai X, Song Q, Fan F, Hu Z, Cheng G, et al. miR223 Inhibits Lipid Deposition and Inflammation by Suppressing Toll-Like Receptor 4 Signaling in Macrophages. Int J Mol Sci. 2015; 16(10):24965-8 